\section{Cooling Method and Fruit Weight: Efficacy of Hot Water Quarantine Treatment for Control of Mexican Fruit Fly in Mango}

\author{
K.C. Shellie ${ }^{1}$ and R.L. Mangan \\ U.S. Department of Agriculture, Agricultural Research Service, Kika de la \\ Garza Subtropical Agricultural Research Center, Crop Quality and Fruit \\ Insects Research Unit, 2413 E. Highway 83, Building 200 Weslaco, TX 78596
}

Additional index words. phytosanitary, disinfestation, heat, pest, hydrocool, Mangifera indica, Anastrepha ludens, Diptera: Tephritidae

\begin{abstract}
The objective of this research was to determine whether immediate cooling of mangoes (Mangifera indica L.) in water or air affected survival of Mexican fruit fly (Anastrepha ludens Loew) larvae. Two tests were conducted with mortality of late third instar Mexican fruit fly larvae evaluated after infested mangoes were immersed in $46.1^{\circ} \mathrm{C}$ water for 65,75 , or 90 minutes depending on fruit weight and immediately cooled in water or air at 22 to $26.5^{\circ} \mathrm{C}$. Results suggest a need to amend the current hot water quarantine dip treatment schedule to require cooling of fruit for $\mathbf{3 0}$ minutes in air. We suggest a 25$\mathrm{g}$ allowance in maximum permitted fruit weight be established for the 65-, 75-, and 90minute dips and a monitoring system used to ensure compliance. Synchronization between maximum permitted fruit weight for each hot water dip duration and commercial sizing practices would facilitate monitoring of fruit weight. We also recommend confirmation of efficacy for the 75-minute treatment of flat-elongated mangoes that weigh $375-570 \mathrm{~g}$.
\end{abstract}

A consistent supply of fresh-market mangoes in the United States requires a treatment be available that ensures fruit are free of insect pests. Immersion of mango (Mangifera indica L.) in hot water (schedule T102-a) is an approved method for meeting quarantine security against the Mexican fruit fly (Anastrepha ludens Loew) [U.S. Dept. of Agriculture (USDA), 1998]. Quarantine security is achieved when no individuals out of at least 93,613 treated insects of the most heat tolerant pest life stage survive the quarantine treatment (Couey and Chew, 1986). Eggs and late third instar larvae are the most heat tolerant life stages for Mexican fruit fly (Mangan et al., 1998). Since eggs, located just below the surface of the mango fruit, receive the most severe heat dose during immersion in hot water, the most difficult life stage to kill using hot water is late third instar larvae, which are often located near the center of the fruit at the endocarp surface. Mangoes, harvested from growing regions where Mexican fruit fly may be present, must be immersed in water at $46.1{ }^{\circ} \mathrm{C}$ for 65,75 , or $90 \mathrm{~min}$,

Received for publication 5 Mar. 2001. Accepted for publication 8 Jan. 2002. We thank the Empacadoras de Mango de Exportacion, A.C. for providing mangoes, USDA-APHIS-PPQ for coordinating research activities, and USDA-ARS technicians Steve Neck, Julie de Leon and Carlos Solis for assistance conducting the research. Mention of a trademark, proprietary product, or vendor does not constitute a guarantee or warranty of the exclusion of other products or vendors that also may be suitable.

${ }^{1}$ Current address: USDA-ARS, Parma Research and Extension Center, 29603 Univ. of Idaho Lane, Parma, ID 83660-6699. according to the respective weight and shape of the mango, before being marketed in any region of the United States with a legislated restriction for Mexican fruit fly. Mangoes weighing $\leq 375 \mathrm{~g}$ require $65 \mathrm{~min}$ of immersion. Mangoes weighing 375 to 500 or $570 \mathrm{~g}$, respectively, for round or flat-elongated cultivars, require immersion for $75 \mathrm{~min}$. Mangoes weighing between 500 or 570 and $700 \mathrm{~g}$ must be immersed for $90 \mathrm{~min}$. No hot water treatment schedule is currently available for fruit weighing $>700 \mathrm{~g}$.

Immediate cooling of fruit after hot water immersion is restricted to cooling in water (by immersion or shower) or air that is at a temperature no cooler than $21{ }^{\circ} \mathrm{C}$ (USDA APHIS-PPQ, 1998). A 30-min delay after removal from hot water is required before fruit can be cooled in air or water at a temperature colder than $21^{\circ} \mathrm{C}$. In the original research on which the current hot water immersion treatment for mango is based, Sharp et al. (1989) cooled the heated fruit in air at $21^{\circ} \mathrm{C}$. Hallman and Sharp (1990) showed that cooling in water at 21 or $27^{\circ} \mathrm{C}$ immediately after removal of mangoes from hot water rapidly decreased the interior temperature of the fruit, and suggested that treatment efficacy may be jeopardized by immediate hydrocooling. Mangan and Hallman (1998) also concluded that hydrocooling immediately after hot water immersion could lower insect mortality enough to jeopardize treatment efficacy and recommended that the efficacy of hot water immersion be tested with large numbers of insects before commercial hydrocooling of heated produce be permitted to continue. Commercial packers wish to cool fruit as soon as possible after heating to facili- tate handling and to minimize heat associated changes in fruit market quality. Shellie (1994) found that immediate cooling in water at $21^{\circ} \mathrm{C}$ did not prevent the development of heatassociated cavities in the flesh of 'Manila' mango. No research is available documenting treatment efficacy for late third instar larvae of A. ludens when mangoes are hydrocooled at $21{ }^{\circ} \mathrm{C}$ immediately after heating. Nor is any data available documenting preservation of mango shelf-life by hydrocooling in $21^{\circ} \mathrm{C}$ water immediately after hot water immersion. The objective of this research was to determine whether cooling mangoes in water or air immediately after a hot water dip quarantine treatment influenced survival of late third instar A. ludens larvae. Another objective of this research was to document whether late third instar A. ludens larvae survived hot water quarantine dips when the weight of the treated mango exceeded the maximum permitted weight by $\approx 70 \mathrm{~g}$.

\section{Materials and Methods}

This research was conducted as a series of two experiments. In the first test, infested mangoes of maximum permitted size (375, 500 , or $700 \mathrm{~g}$ ) were immersed in hot water for 65,75 , or $90 \mathrm{~min}$, respectively, and immediately cooled in water at 22 to $26.5^{\circ} \mathrm{C}$. In the second test, infested mangoes equal to or $70 \mathrm{~g}$ heavier than maximum permitted size $(375$, 500 , or $700 \mathrm{~g}$ ) were immersed in hot water for 65,75 , or $90 \mathrm{~min}$, respectively, and then immediately cooled in water or in air at 22 to $26.5^{\circ} \mathrm{C}$. Mangoes utilized for all tests were received from Mexico (Test 1) or South America (Test 2) in five separate shipments to the USDA-Agricultural Research Service (USDA-ARS) laboratory in Weslaco, Texas, during the months of Sept. 2000 through Jan. 2001. Mango cultivars in each shipment were not specified, but similar weight fruit of mature green or color-break stage of maturity in each shipment were allocated into treatment groups of 20 mangoes each. The range in weight among fruit within each treatment group was no more than $25 \mathrm{~g}$. Ten fruit from each shipment were designated as controls for each treatment group. Control fruit were infested, but remained in air at 22 to $26.5{ }^{\circ} \mathrm{C}$ while treated fruit were heated and cooled.

Two 608-L insulated, fiberglass baths located inside a temperature-controlled building maintained at $23{ }^{\circ} \mathrm{C}$ were used to heat or cool fruit. Each bath was filled with tap water and equipped with a float valve shut off. Immersed heating coils were used to maintain an average hot bath temperature for all treatment replications in Test 1 and 2 of $45.8 \pm 0.2$ and $46.1 \pm$ $0.2{ }^{\circ} \mathrm{C}$, respectively. The other bath was used to cool fruit and had no direct temperature control. The temperature of the tap water, building, and heat liberated from cooling fruit maintained the temperature of the cooling bath at an average in Test 1 and 2 of $26.5 \pm 0.4$ and $24.1 \pm 1.1^{\circ} \mathrm{C}$, respectively.

Fruit were dipped in hot water by placing 20 fruit into a six-sided mesh $\left(2.54 \mathrm{~cm}^{2}\right.$ opening), plastic bin (overall $60 \mathrm{~cm}$ long $\times 40 \mathrm{~cm}$ 
wide $\times 21 \mathrm{~cm}$ deep). Two bins containing 20 fruit each were aligned vertically above and below a similar sized empty treatment bin. The three bins were positioned into a steel carrier and lowered into the $608-\mathrm{L}$ bath by use of an overhead boom and electric lift. Timing of hot water dip duration was initiated when the top bin was immersed at least $10 \mathrm{~cm}$ below the surface of the hot water ( $\approx 1$ min delay). The hot water dip treatment was terminated after 65,75 , or 90 min by raising the bins out of the hot water bath with the electric lift and overhead boom. Within 2 min after fruit were removed from hot water, the bottom bin containing 20 fruit was immersed into the $608-\mathrm{L}$ bath of water at 22 to $26.5^{\circ} \mathrm{C}$. The fruit in the bottom bin were immersed at least $10 \mathrm{~cm}$ below the surface of the water, and remained immersed until the center temperature of all 20 fruit was $35^{\circ} \mathrm{C}$ or cooler. The top bin containing the other 20 hot water dipped fruit remained suspended in air at $23{ }^{\circ} \mathrm{C}$ above the cool water bath until the immersed bin of fruit was removed from the cool water bath.

The temperature of the baths and the center of the mango fruit was recorded at $60 \mathrm{~s}$ intervals throughout heating and cooling. One 36gauge $(0.13 \mathrm{~mm})$ thermocouple was inserted at the surface of the endocarp in the center of each of five fruit per treatment group as described by Shellie and Mangan (2000). Three similar sized thermocouples were used to record temperatures at the bottom, middle, and top of the water bath. All 36-gauge $(0.13$ $\mathrm{mm}$ ), type $\mathrm{T}$ (deviation $0.3^{\circ} \mathrm{F}$ at $212.4^{\circ} \mathrm{F}$ ), plastic-tipped thermocouples were connected to a data logger [Data Electronics Datataker DT500 Series 2 (dataTaker Pty, Laguna Hills, Calif.)].

About $2 \mathrm{~h}$ prior to each hot water dip treatment, each individual fruit per treatment group was numbered, weighed, and artificially infested with 50 late third instar (last stage before pupation) larvae utilizing a method described by Mangan and Ingle (1994) that approximates natural infestations in which female fruit flies deposit eggs into fruit in clumps that develop into pockets of larvae. There was no chance that natural infestation could have confounded the results of our tests because the oldest wild larvae that could have been encountered in fruit of the maturity stages that we used would have been first instars, which cannot be mistaken for the larger, late third instars we used for artificial infestation. The market quality of the fruit at the time of infestation and treatment was similar to that of mangoes commercially hot water dipped, i.e. mature green and free of visible external defects. The late third instar larvae used in both experiments to infest the fruit were obtained from a colony founded in 2000 with material from Mexico, and maintained at the USDAARS laboratory in Weslaco, Tex. Larvae were reared on a standard fruit fly diet of rehydrated carrot powder and torula yeast (Spishakoff and Hernandez Davila, 1968) in a room maintained at $26.7 \pm 2{ }^{\circ} \mathrm{C}$. The third instars used in this research were removed from the rearing medium at $9 \mathrm{~d}$ of age.

Treated and control fruit were held over- night in air at $21^{\circ} \mathrm{C}$, and larvae were removed from fruit the following morning. Larvae removed from 10 of the 20 treated fruit in each treatment group were bulked together into a plastic container with vermiculite. Two plastic containers, each holding $\approx 500$ live or dead larvae, were independently evaluated for each treatment group. Larvae removed from the 10 control fruit for each treatment group were also bulked into a single plastic container. After larvae were removed from the fruit, the mango fruit pulp was discarded. The larvae removed from the fruit were stored inside the sealed, air ventilated plastic containers at $23{ }^{\circ} \mathrm{C}$ for $7 \mathrm{~d}$. After $7 \mathrm{~d}$ of storage, the vermiculite was sifted, and the actual number of pupae encountered in each plastic container was recorded. Any pupae encountered after $7 \mathrm{~d}$ of storage in vermiculite were considered survivors of the hot water dip treatment. Eclosion was not evaluated.

In the first experiment (Test 1), a single 65-, 75-, or 90-min hot water dip with immediate cooling in water at 22.0 to $26.5^{\circ} \mathrm{C}$ was conducted. Forty fruit each weighing $375 \mathrm{~g}$ were hot water dipped for 65 min with a total of 2000 larvae treated. Twenty fruit weighing 500 or $700 \mathrm{~g}$ were hot water dipped for 75 or $90 \mathrm{~min}$, respectively, resulting in a total of 1000 larvae treated per treatment group.

In the second experiment (Test 2), each $65-, 75-$, or 90-min dip treatment was replicated three times with 20 similarly sized fruit per treatment group, resulting in a total of 3000 larvae treated per treatment group. The five treatment groups, based upon fruit weight, were $375,375+, 500,500+$, and $700 \mathrm{~g}$, for the 65-, 75-, or 90-min dip treatments. The fruit allocated to the $375+$ or $500+$ treatment groups weighed $70 \mathrm{~g}$ more than the fruit allocated to

Table 1. Average fruit weight and percent mortality of late third instar Mexican fruit fly larvae in artificially infested mangoes immersed in $46.1^{\circ} \mathrm{C}$ water for 65,75 , or $90 \mathrm{~min}$. After heating, mangoes were cooled in 22.0 to $26.5^{\circ} \mathrm{C}$ water or $23^{\circ} \mathrm{C}$ air. Controls for each respective treatment group were infested and stored in air at $23{ }^{\circ} \mathrm{C}$.

\begin{tabular}{|c|c|c|c|c|c|}
\hline Dip time (min) & Test & Fruit $w^{\mathrm{z}}[\mathrm{g}(\mathrm{SD})]$ & Cooled $\geq 21^{\circ} \mathrm{C}$ & Mortality $^{\mathrm{y}}[\%(\mathrm{SD})]$ & Larvae treated \\
\hline 65, Control & 1 & 486.7 & Control & 28.5 & 400 \\
\hline 65 & & $362.0(2.1)$ & Water & $95.2 \quad(2.4)$ & 2000 \\
\hline 65, Control & 2 & $432.7(35.3)$ & Control & 7.9 (1.3) & 3000 \\
\hline 65 & & $383.2(18.9)$ & Air & 100 & 3000 \\
\hline 65 & & $382.6(18.5)$ & Water & $96.8 \quad(5.1)$ & 3000 \\
\hline 65 & & $447.7(3.7)$ & Air & $99.9 \quad(0.2)$ & 3000 \\
\hline 65 & & $442.1 \quad(6.6)$ & Water & $79.9(12.6)$ & 3000 \\
\hline 75, Control & 1 & 562.7 & Control & 28.8 & 400 \\
\hline 75 & & $453.5(43.4)$ & Water & $99.3 \quad(0.4)$ & 1000 \\
\hline 75, Control & 2 & $540.8(41.3)$ & Control & $5.9 \quad(3.4)$ & 3000 \\
\hline 75 & & $501.6(4.2)$ & Air & $100 \quad(0)$ & 3000 \\
\hline 75 & & $494.4(13.8)$ & Water & $99.3 \quad(1.4)$ & 3000 \\
\hline 75 & & $568.1 \quad(18.4)$ & Air & $99.9 \quad(0.3)$ & 3000 \\
\hline 75 & & $571.6(15.09)$ & Water & $95.4 \quad(4.0)$ & 3000 \\
\hline 90, Control & 1 & 669.9 & Control & 0.6 & 500 \\
\hline 90 & & 686.9 (16.9) & Water & $(0.0)$ & 1000 \\
\hline 90, Control & 2 & $649.0(21.3)$ & Control & $10.4 \quad(5.6)$ & 1500 \\
\hline 90 & & $711.2(10.0)$ & Air & 100 & 3000 \\
\hline 90 & & $706.8 \quad(10.1)$ & Water & $96.17(6.0)$ & 3000 \\
\hline
\end{tabular}

${ }^{\mathrm{z}}$ Average infested pretreatment fruit weight calculated as the sum of the average pretreatment weight of infested fruit per container divided by the total number of containers evaluated in all treatment replications. Numbers in parentheses are the standard deviations of fruit weights per container over all treatment replications.

${ }^{y}$ Average percent mortality per container calculated as the sum of [ $(500-$ number of pupae per container $)$ / 500] * 100 divided by the total number of containers evaluated in all treatment replications. Numbers in parentheses are the standard deviations of percent mortality per container over all treatment replications. 


\section{Results and Discussion}

When fruit did not exceed the maximum permitted weight per treatment time and were cooled in air, no larvae survived the hot water dip treatment (Table 1). For example, all 3000 larvae recovered from fruit weighing $383 \pm 19 \mathrm{~g}$ were killed after the fruit were immersed in hot water for $65 \mathrm{~min}$ and cooled in air. The same was true for the 3000 larvae recovered from fruit weighing $502 \pm 4 \mathrm{~g}$ that were immersed for $75 \mathrm{~min}$ and cooled in air, and fruit weighing $711 \pm 10 \mathrm{~g}$ that were immersed for $90 \mathrm{~min}$ and cooled in air. These results support the conclusion of Sharp et al. (1989), who claimed that a 65-, 75-, or 90-min immersion in $46.1{ }^{\circ} \mathrm{C}$ water could provide Probit 9 level quarantine security against Mexican fruit fly for fruit weighing 375,500 , or $700 \mathrm{~g}$, respectively, when cooled in ambient temperature air.

Larval survivors were encountered when fruit of maximum permitted weight were immediately cooled in water at 22.0 to $26.5^{\circ} \mathrm{C}$ (Table 1). Larval survivors were also encountered when the weight of the fruit exceeded maximum permitted weight by $\approx 70 \mathrm{~g}$. When fruit were immediately cooled in water after heating, $\approx 4 \%$ of 5000 larvae survived infestation in fruit weighing $362 \pm$ $2 \mathrm{~g}$ (Test 1 ) or $383 \pm 19 \mathrm{~g}$ (Test 2) that were immersed for $65 \mathrm{~min}, \approx 0.4 \%$ of 4000 larvae survived infestation in fruit weighing $454 \pm$ $43 \mathrm{~g}$ (Test 1) or $494 \pm 14 \mathrm{~g}$ (Test 2) that were immersed for $75 \mathrm{~min}$, and $\approx 2 \%$ of 4000 larvae survived infestation in fruit weighing $687 \pm$ $17 \mathrm{~g}$ (Test 1) or $707 \pm 6 \mathrm{~g}$ (Test 2) that were immersed for $90 \mathrm{~min}$.

Larval survivors were also recovered from infested oversized fruit that had been immersed in hot water for 65 or $75 \mathrm{~min}$, irrespective of cooling method after heating (Table 1). However, larval survivorship was highest when oversized, infested fruit were cooled in water. About $4.5 \%$ to $20 \%$ more larvae were able to survive immersion in hot water inside oversized fruit immersed for 75 or $65 \mathrm{~min}$, respectively, when the fruit were cooled in water vs. air.

The temperature at the center of the fruit continued to increase for $\approx 8-10 \mathrm{~min}$ after heat-treated fruit were removed from the hot water bath (Fig. 1). The temperatures of the hot and ambient temperature water baths were similar for each treatment group replication in each of the two experiments (Fig. 2). The center temperature of fruit immediately immersed in ambient water after removal from the hot water bath decreased more rapidly than that of fruit cooled in air. These results support the findings of Hallman and Sharp (1990) who reported a $7{ }^{\circ} \mathrm{C}$ disparity in mango fruit center temperature $20 \mathrm{~min}$ after cooling in air or water of similar temperature.

Maximum fruit center temperature did not appear to be the sole determinant of larval mortality (Fig. 1). For example, fruit treated for 65 or 75 min in Test 1 reached a higher maximum fruit center temperature yet survivorship was higher for larvae recovered from these fruit. An initial difference in fruit center temperature, such as that observed for fruit treated in Test $1\left[\approx 2{ }^{\circ} \mathrm{C}\right.$ warmer $\left(24\right.$ to $\left.\left.25^{\circ} \mathrm{C}\right)\right]$ persisted throughout the hot water dip treatment, so that fruit initially warmer prior to hot water dipping, reached a higher maximum center temperature upon completion of the hot water treatment. Fruit dipped for 65 or $75 \mathrm{~min}$ in Test 1 were also slightly $(\approx 20 \mathrm{~g})$ smaller than fruit dipped for 65 or $75 \mathrm{~min}$ in Test 2 . However, some larvae survived in each of these tests.

Results from this research suggest that efficacy of hot water as a quarantine treatment is affected by cooling method after heating and by fruit weight. Our results demonstrate that cooling fruit in ambient temperature water immediately after heating jeopardizes the efficacy of hot water as a quarantine treatment for Mexican fruit fly. Our results also demonstrate that treatment efficacy is jeopardized when fruit weight exceeds maximum permitted weight by $70 \mathrm{~g}$.

To ensure that a Mexican fruit fly population is not inadvertently introduced into the United States during marketing of fresh mango, results from this research suggest a need to amend the APHIS PPQ treatment schedule (T102-a) for fruit from growing regions where Mexican fruit fly is a recognized pest (1998). We suggest the treatment schedule be amended to require that fruit be cooled in air of a temperature warmer or equal to $21^{\circ} \mathrm{C}$ for the first $30 \mathrm{~min}$ after removal from a hot water dip treatment. After $30 \mathrm{~min}$ of cooling in air, the
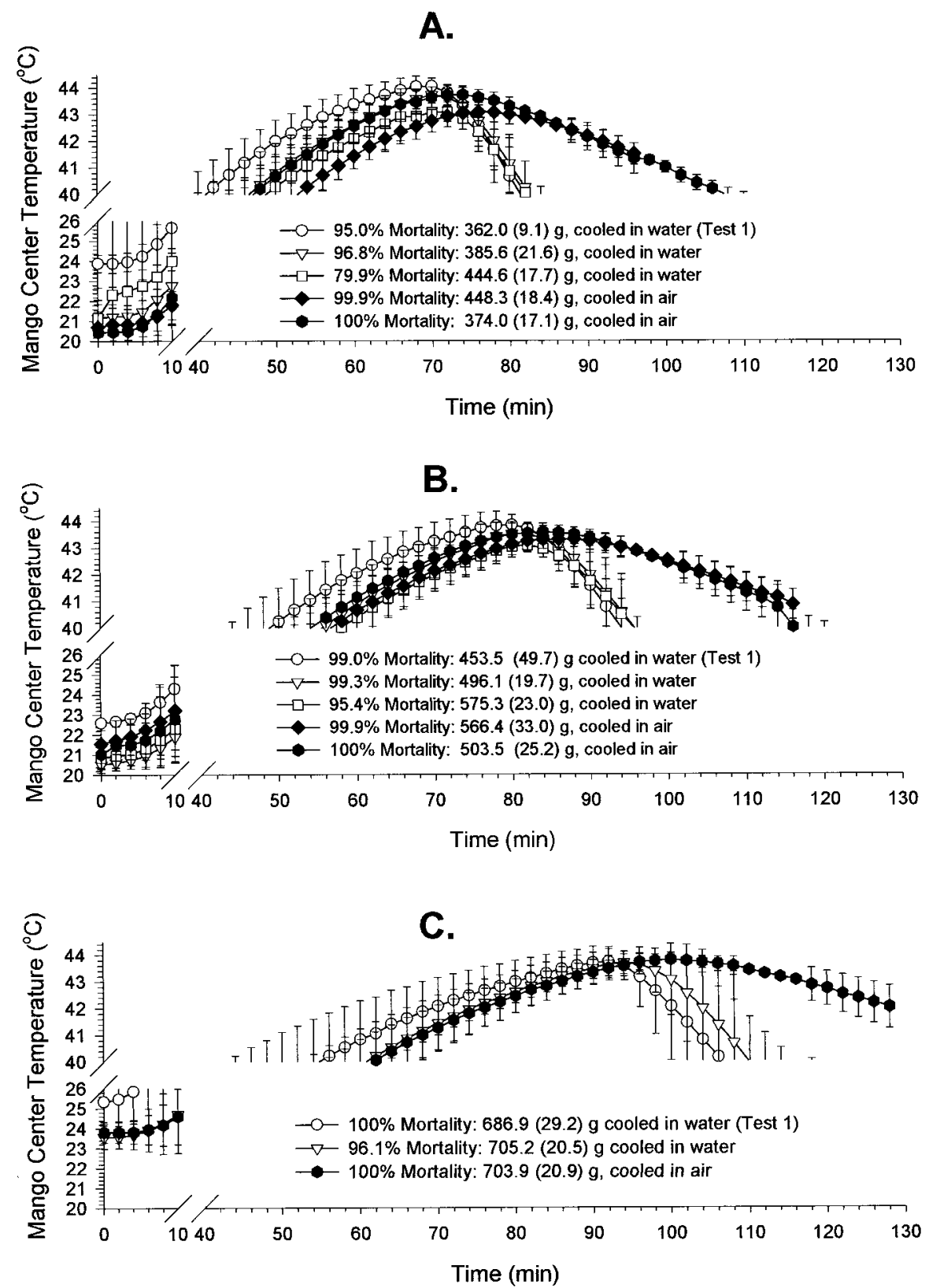

Fig. 1. Average temperature at center of mango fruit during immersion in water at $41.1^{\circ} \mathrm{C}$ and cooling in 22.0 to $26.5^{\circ} \mathrm{C}$ water or $23^{\circ} \mathrm{C}$ air. Open symbols signify cooling in water and closed symbols signify cooling in air. Graphs A, B, and C depict the 65-, 75-, or 90-min hot water dip. Error bars are based on average values of the 5 (Test 1) or 15 (Test 2) fruit in each treatment group. Standard deviations follow fruit weight in parentheses. 


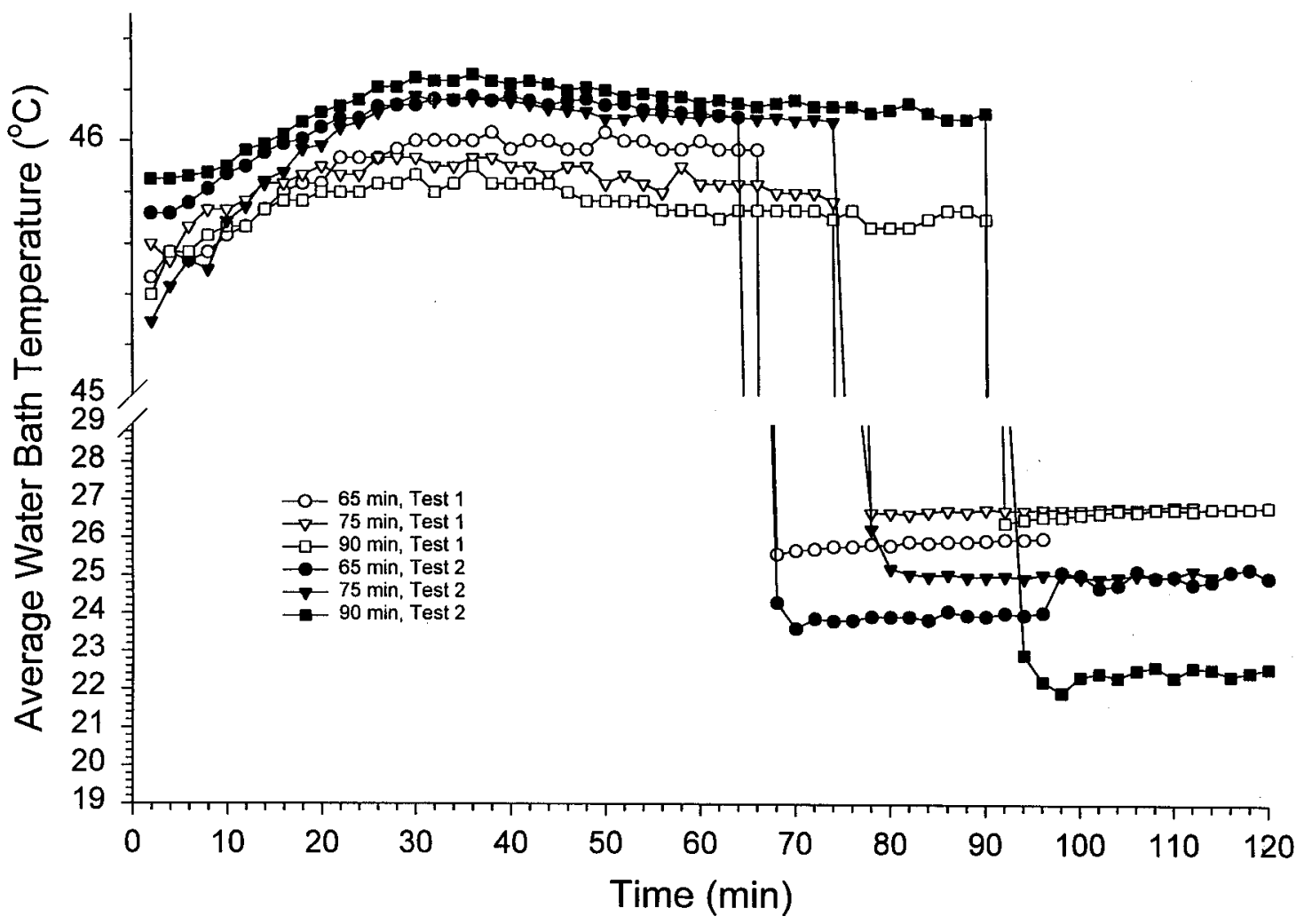

Fig. 2. Average temperature of the hot and ambient temperature water baths used to heat or cool infested mango fruit in Tests 1 and 2 . Open symbols signify Test 1 , and closed symbols signify Test 2 . Standard error for temperature probes located at the bottom, middle, and top of the water bath is mentioned in the text.

fruit could be cooled in any temperature of air or water. We also suggest that a $25 \mathrm{~g}$ allowance in maximum permitted fruit weight be established for the 65-, 75-, and 90-min hot water dip treatments, and suggest a monitoring system be established to ensure that fruit exceeding the maximum permitted weight are immersed in hot water for a longer period of time. For example, a fruit weighing $401 \mathrm{~g}$ should require a 75 -instead of a 65 -min hot water dip. Fruit $>726 \mathrm{~g}$, should not be permitted entry into the United States. Synchronization between maximum permitted fruit weight and commercial sizing practices would facilitate monitoring of fruit weight. For example, some fruit used to conduct this research arrived in $5-\mathrm{kg}$ boxes commercially sized as 7,8 , or 10 (corresponding to the number of fruit in a $5-\mathrm{kg}$ box). We documented an average fruit weight of $543 \pm 53,534 \pm 42$, and $418 \pm 29 \mathrm{~g}$ in three boxes each of size 7,8 , or 10 . These data suggest that size 7 and 8 mangoes should require immersion for $90 \mathrm{~min}$, while size 10 mangoes should require a 75-min dip. We also recommend confirmation of efficacy for the 75-min hot water dip treatment for flat-elongated mangoes heavier than $525 \mathrm{~g}$ because results from this research indicate that a 75-min immersion in hot water will not provide quarantine security for fruit weighing $570 \mathrm{~g}$.

\section{Literature Cited}

Couey, H. and V. Chew. 1986. Confidence limits and sample size in quarantine research. J. Econ. Entomol. 79:887-890.

Hallman, G.J. and J. Sharp. 1990. Mortality of Caribbean fruit fly (Diptera: Tephritidae) larvae infesting mangoes subjected to hot-water treatment, then immersion cooling. J. Econ. Entomol. 83:2320-2323.

Mangan, R.L. and G. J. Hallman. 1998. Temperature treatments for quarantine security: New approaches for fresh commodities, p. 201-234. In: G.J. Hallman and D.L. Denlinger (eds.). Temperature sensitivity in insects and application in integrated pest management. Westview Press, Boulder, Colo.

Mangan, R.L. and S.J. Ingle. 1994. Forced hot air quarantine treatment for grapefruit infested with Mexican fruit fly. J. Econ. Entomol. 87:15741579.
Mangan, R.L., K.C. Shellie, S.J. Ingle, and M.J. Firko. 1998. High temperature forced-air treatments with fixed time and temperature for 'Dancy' tangerines, 'Valencia' oranges, and 'Rio Star' grapefruit. J. Econ. Entomol.91:933939.

Sharp, J.L., M.T. Ouye, S.J. Ingle, and W.G. Hart. 1989. Hot-water quarantine treatment for mangoes from Mexico infested with Mexican fruit fly and West Indian fruit fly (Diptera: Tephritidae). J.Econ. Entomol. 82:1657-1662.

Shellie, K.C. 1994. Quality of 'Manila' mango after heat treatments for fruit fly disinfestation. HortScience 29:483. (Abstr.)

Shellie, K.C. and R.L. Mangan. 2000. Postharvest disinfestation heat treatments: Response of fruit and fruit fly larvae to different heating media. Postharvest Biol. and Technol. 21:5160.

Spishakoff, L.M. and J.G. Hernandez Davila. 1968. Dried torula yeast as a substitute for brewer's yeast in the larval rearing medium for the Mexican fruit fly. J. Econ. Entomol. 61:859860.

U.S. Dept. of Agriculture. 1998. Plant protection and quarantine treatment manual. U.S. Dept. Agr., Animal and Plant Health Inspection Serv., Hyattsville, Md. 